\title{
Meningkatkan Minat Belajar Siswa Menggunakan Aplikasi Multimedia Pembelajaran
}

\author{
Tri Sugihartono ${ }^{[1]}$, Rendy Rian Chrisna Putra ${ }^{[2]}$ \\ Program Studi Tenik Informatika ${ }^{[1] ~[2] ~}$ \\ STMIK AtmaLuhur ${ }^{[1] ~[2] ~}$ \\ Jl. Jend. Sudirman, Selindung Baru, Pangkalpinang \\ trisugihartono@atmaluhur.ac.id ${ }^{[1]}$,rendyriancp@atmaluhur.ac.id ${ }^{[2]}$
}

\begin{abstract}
The rapid development of science and information technology, electronic technology is also growing rapidly. Indirectly, human lifestyles are influenced by the presence of various sophisticated electronic equipment. With the development of technology and computer-based electronic equipment, many people already have smartphones and tablets. These tools can help facilitate daily activities, for example student learning with Android-based applications. The problem with early childhood is a limited knowledge base, they need an understanding of letters, numbers, animal types, and fruit names. The learning patterns of children who like to play greatly affect the concentration of children in learning. They are easily bored with theoretical material that is conveyed verbally by the teacher and parents, children understand the material in the form of images faster. Therefore, this study discusses the application of multimedia learning to increase student interest in learning that can help in their learning process. This study uses data collection techniques using a questionnaire method, while the data obtained using primary data that is quantitative data. The results of this study are as many as 30 users feel challenged after using multimedia learning applications. and 1 person who feels bored after using a multimedia application. In addition, of the 50 users, the majority received a score of $80-100$, while those who received a score of 0-50 only 1 person. Thus it can be concluded that with the presence of multimedia learning applications, students can more easily understand and can increase interest in learning, feel interested and challenged with the exercise features in the form of multimedia.
\end{abstract}

Keywords-Learning Application ; Education; Android; Multimedia; School

Abstrak-Pesatnya perkembangan ilmu pengetahuan dan teknologi informasi, teknologi elektronik juga berkembang pesat. Secara tidak langsung, gaya hidup manusia dipengaruhi oleh kehadiran berbagai peralatan elektronik yang canggih. Dengan perkembangan teknologi dan peralatan elektronik berbasis komputer, banyak orang sudah memiliki smartphone dan tablet tersebut. Alat-alat ini dapat membantu memfasilitasi kegiatan sehari-hari, misalnya belajar siswa dengan aplikasi berbasis Android. Masalah dengan anak usia dini adalah basis pengetahuan yang terbatas, mereka membutuhkan pemahaman tentang huruf, angka, jenis hewan, dan nama buah. Pola belajar anak-anak yang suka bermain sangat memengaruhi konsentrasi anak dalam belajar. Mereka mudah bosan dengan materi teoretis yang disampaikan secara verbal oleh guru dan orang tua, anak memahami materi dalam bentuk gambar lebih cepat. Oleh karena itu, penelitian ini membahas penerapan pembelajaran multimedia untuk meningkatkan minat belajar siswa yang dapat membantu dalam proses pembelajaran mereka. Penelitian ini menggunakan teknik pengumpulan data menggunakan metode kuesioner, adapun data yang diperoleh menggunakan data primer yang bersifat data kuantitatif. Hasil penelitian ini adalah sebanyak 30 user merasa tertantang setelah menggunakan aplikasi multimedia pembelajaran. dan 1 Orang yang merasa bosan setelah menggunakan aplikasi multimedia. Selain itu juga dari 50 user,mayoritas memperoleh score 80-100, sedangkan yang mendapat nilai 0-50 hanya 1 orang. Dengan demikian dapat disimpulkan bahwa dengan adanya aplikasi pembelajaran multimedia, siswa dapat lebih mudah memahami dan dapat meningkatkan minat belajar, merasa tertarik dan tertantang dengan fitur latihan dalam bentuk multimedia.

Kata Kunci-Aplikasi Pembelajaran; Pendidikan; Android; Multimedia; Sekolah.

\section{PENDAHULUAN}

Berkembangnya ilmu informasi dan teknologi yang sangat cepat[2][8], teknologi elektronik pun ikut berkembang dengan pesatnya. Secara tidak langsung gaya hidup manusia ikut terpengaruh dengan adanya berbagai macam peralatan elektronik yang canggih. Dengan berkembangnya teknologi dan peralatan-peralatan elektronik yang berbasis komputer sudah banyak dimiliki masyarakat seperti smartphone dan tablet. Peralatan-peralatan tersebut dapat membantu memudahkan kegiatan sehari-hari[3][4][5][6], contohnya pembelajaran siswa dengan aplikasi berbasis android[1][7].

Permasalahan yang ada saaat ini adalah anak anak mudah bosan dengan materi teoritis, dan sangat sulit menangkap pengetahuan secara lisan, anak lebih cepat memahami materi berupa gambar. Terbatasnya pengetahuan dasar, mereka membutuhkan pemahaman mengenai huruf, angka, jenis hewan, dan nama-nama buah. Pola belajar anak yang senang bermain sangat mempengaruhi konsentrasi anak dalam belajar. Oleh karena itu, anak-anak usia dini membutuhkan aplikasi edukasi yang dapat membantu dalam proses belajar mereka[9].

Dalam penelitian [1] mengungkapkan bahwa aplikasi multimedia pembelajaran sangat membantu dalam proses pembelajaran yang diajarkan guru. Serta dapat menghilangkan rasa bosan pada siswa.Dalam penelitian [9] mengungkapkan bahwa setelah adanya aplikasi multimedia pembelajaran tilawatil quran, para santri semakin lebih cinta membaca 
alquran dan bisa membaca alquran dengan fasih.

Dalam penelitian [5] mengungkapkan bahwa aplikasi pembelajaran dapat meningkatkan keterkaitan belajar anak, dikarenakan aplikasi berisi fitur fitur yang menarik daam bentu gambar dan suara.Dalam penelitian [3] mengungkapkan bahwa anak lebih termotivasi untuk belajar dan lebih mudah menerima pengatahuan dari materi yang sudah disediakan, serta dapat membantu proses belajar yang efektif dan efisien.

Berdasarkan permasalahan dan studi literatur diatas maka Dalam penelitian ini, penulis akan meneliti dan mengevaluasi pengaruh dari aplikasi pembelajaran kepada siswa SD terhadap minat belajar dan pemahaman siswa.

\section{METODOLOGI PENELITIAN}

\section{A. Metode Pengembangan Sistem}

Metode pendekatan sistem yang penulis gunakan adalah metode pendekatan sistem yang berorientasi objek (ObjectOriented Analysis and Design).

\section{B. Tools Pengembangan Sistem}

Tools Pengembangan sistem yang digunakan adalah model diagram UML (Unified Modelling Language).

Use case diagram yang terdapat beberapa dokumen yang menunjukan bagaimana prosedur penjadwalan.

Activity Diagram menggambarkan rangkaian aliran dari aktivitas, digunakan untuk mendeskripsikan aktivitas yang dibentuk dalam suatu operasi sehingga dapat juga digunakan untuk aktivitas lainnya seperti use case atau interaksi.

Sequence Diagram menggambarkan kolaborasi dinamis antara sejumlah object. Kegunaanya untuk menunjukkan rangkaian pesan yang dikirim antara object juga interaksi antara object, sesuatu yang terjadi pada titik tertentu dalam eksekusi sistem.

Class diagram adalah model statis yang menggambarkan struktur dan deskripsi class serta hubungannya antara class. Class diagram mirip ER-Diagram pada perancangan database, bedanya pada ER-diagram tidak terdapat operasi/methode tapi hanya atribut. Class terdiri dari nama kelas, atribut dan operasi/method

\section{Model Pengembangan Sistem}

Dalam merancang sebuah sistem yang menggunakan mekanisme pengembangan sistem dengan waterfall [10]

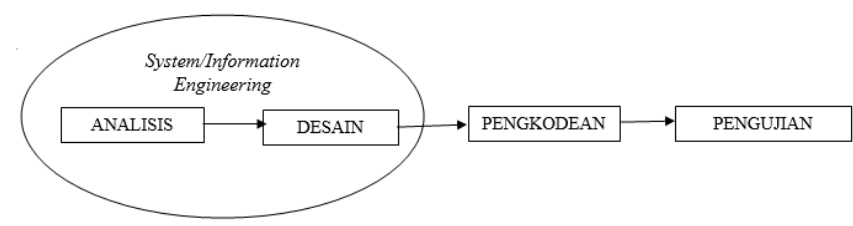

Gambar 1. Model Waterfall dalam Pengembangan Sistem

Pada tahap analisis ini adalah melakukan pengumpulan data yaitu dengan field reserch (metode penelitian)/observasi, dan interview (wawancara) dan dengan cara literatur yaitu dengan dokumentasi terhadap kebutuhan yang diinginkan pemakai, baik dalam model interface, teknik, prosedural maupun dalam teknologi yang akan digunakan. Penulis menggunakan metode berorientasi objek dengan membuat identifikasi kebutuhan yang meliputi analisa proses bisnis, activity diagram.

Kebutuhan sistem terbagi menjadi dua bagian yakni kebutuhan fungsional dan non fungsional. Analisis Kebutuhan Fungsional meliputi Sistem dapat menampilkan menu utama aplikasi, halaman pengenalan Huruf, halaman pengenalan Angka, halaman pengenalan Hewan, halaman pengenalan Buah, halaman soal latihan, dan informasi mengenai aplikasi.

Adapun Analisa Kebutuhan Non Fungsional meliputi Kebutuhan Perangkat Keras, dan Perangkat Lunak.Kebutuhan perangat keras, kebutuhan perangkat lunak, dan kebutuhan pengguna di paparkan dalam bentuk tabel berikut ini.

Tabel 1. Spesifikasi Perangkat Keras Smartphone

\begin{tabular}{|c|c|c|}
\hline No & Nama & Spesifikasi \\
\hline 1. & Memori Internal & $8 \mathrm{~GB}$ \\
\hline 2. & RAM & $1.5 \mathrm{~GB}$ \\
\hline 3. & Layar & Min. 1280x720px \\
\hline 4. & OS & Min. Android 5.1 \\
\hline
\end{tabular}

Tabel 2. Spesifikasi Perangakat Keras Komputer

\begin{tabular}{|c|c|c|}
\hline No & Nama & Spesifikasi \\
\hline 1. & Processor & $\begin{array}{r}\text { Inter Core i3-3217U, up to } \\
1.6 \mathrm{GHz}\end{array}$ \\
\hline 2. & Monitor & Resolusi 1366 x 768 pixel \\
\hline 3. & VGA Card & $2 \mathrm{~GB}$ \\
\hline 4. & Harddisk & HDD 500 GB \\
\hline 5. & Memory & RAM 6 GB \\
\hline
\end{tabular}

Tabel 3. Analisa Kebutuhan Software

\begin{tabular}{|c|c|c|}
\hline No & Nama Perangkat & Spesifikasi \\
\hline 1. & Sistem Operasi & $\begin{array}{c}\text { Windows } 7 / 8 / 10 \\
\text { Profesional }\end{array}$ \\
\hline 2. & Android Studio & Android Studio 3.4.1 \\
\hline 3. & JRE & JRE 1.8.0 \\
\hline 4. & JDK & OpenJDK \\
\hline
\end{tabular}

Tabel 4. Analisa Kebutuhan Pengguna

\begin{tabular}{|c|l|l|l|}
\hline $\begin{array}{c}\text { Tipe } \\
\text { Pengguna }\end{array}$ & Hak Akses & $\begin{array}{c}\text { Tingkat } \\
\text { Keterampilan }\end{array}$ & $\begin{array}{c}\text { Jenis } \\
\text { Pelatihan }\end{array}$ \\
\hline $\begin{array}{c}\text { Admin } \\
\text { Web }\end{array}$ & $\begin{array}{l}\text { Dapat } \\
\text { Mengakses } \\
\text { administrator } \\
\text { aplikasi }\end{array}$ & $\begin{array}{l}\text { Dapat } \\
\text { menggolah } \\
\text { database dan } \\
\text { dapat } \\
\text { menggunakan } \\
\text { diperlukan } \\
\text { pelatihan } \\
\text { khusus. }\end{array}$ & $\begin{array}{l}\text { internet } \\
\text { Dengguna }\end{array}$ \\
& $\begin{array}{l}\text { Dapat } \\
\text { Mengakses } \\
\text { aplikasi }\end{array}$ & $\begin{array}{l}\text { mengoprasikan } \\
\text { ponsel } \\
\text { pembelajaran. }\end{array}$ & $\begin{array}{l}\text { Tidak } \\
\text { diperlukan } \\
\text { pelatihan } \\
\text { khusus. }\end{array}$ \\
& operasi android. & \\
\hline
\end{tabular}


Analisis Sistem Berjalan yang terjadi pada sistem pembelajaran saat ini adalah Guru atau orangtua memberikan pelajaran tentang pengenalan huruf, angka, hewan dan buah, siswa atau anak mendengarkan dan menerima pelajaran tersebut, jika siswa mengerti maka guru atau orangtua memberikan materi untuk latihan dan jika tidak mengerti guru atau orang tua menjelaskan kembali.

Berdasarkan analisis proses bisnis tersebut maka penulis menggambarkan Activity Diagram dari sistem berjalan sebagai berikut :

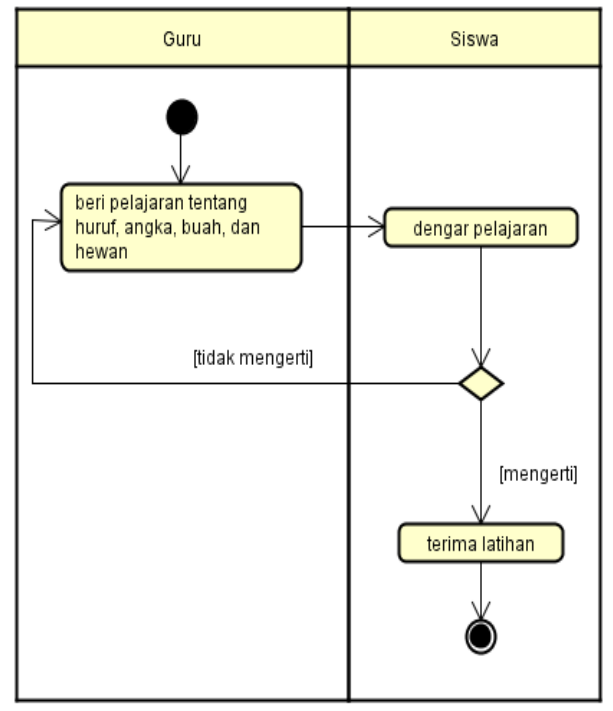

Gambar 2. Activity Diagram Sistem Berjalan

Dalam tahap Desain penulis akan merancang desain dan model aplikasi yang akan dikembangkan berdasarkan hasil analisa pada tahap sebelumnya. Analisis sistem pada tahap ini akan mendeteksi dan mengidentifikasi sejauh mana pemodelan yang dibuat dapat diterima oleh user. Perbaikanperbaikan apa yang diinginkan pengguna atau bahkan harus merubah secara keseluruhan.

Pada Perancangan Sistem dalam penelitian ini dilakukan Tahapan identifikasi sistem usulan adalah tahapan untuk memberikan gambaran mengenai Aplikasi Pembelajaran yang akan diusulkan. Tahapan perancangan sistem merupakan penerjemah dari keperluan atau data yang telah dianalisis kedalam bentuk yang mudah dimengerti oleh pemakai (user). Pada perancangan sistem ini penulis menggunakan Diagram UML yang terdiri dari Activity Diagram dan Usecase Diagram.

Usecase Diagram merupakan penggambaran siapa aja aktor yang terlibat melakukan proses kegiatan pembelajaran. Pada Usecase Diagram yang diusulkan dibuat agar pengguna sistem paham dan mengerti mengenai sistem yang akan dibuat, berikut Usecase diagram yang diusulkan.

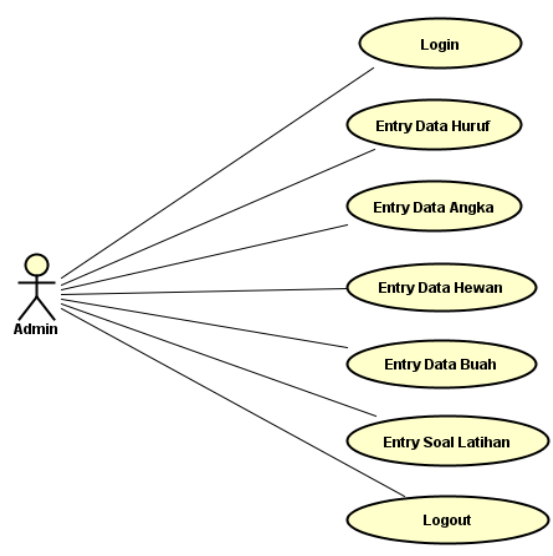

Gambar 3. Usecase Diagram Admin

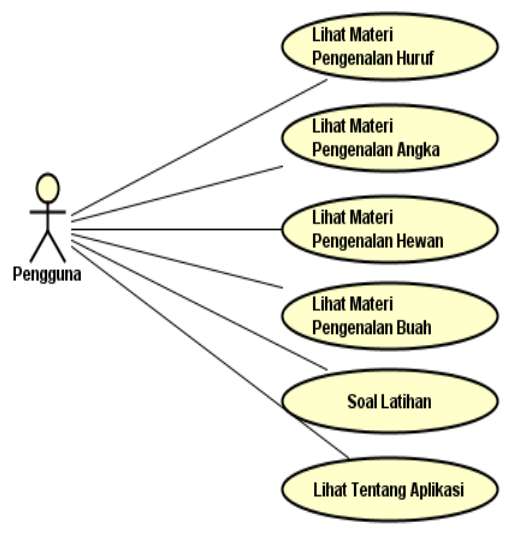

Gambar 4. Usecase Diagram Pengguna

\section{Rancangan Layar Dashboard}

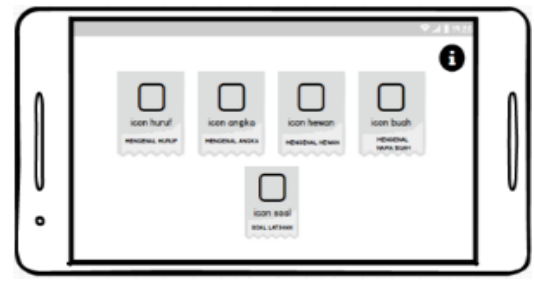

Gambar 5. Rancangan Layar Dashboard

Gambar diatas merupakan rancangan layar untuk halaman dashboar yang berisi beberapa menu.

\section{Rancangan Layar Mengenal Huruf}

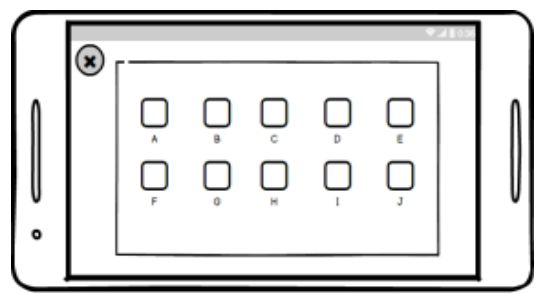

Gambar 6. Rancangan Layar Mengenal Huruf 
Gambar diatas merupakan rancangan layar untuk halaman huruf, di halaman ini berisi pembelajaran mengenai buruf huruf yang akan dipelajari.

\section{Rancangan Layar Mengenal Angka}

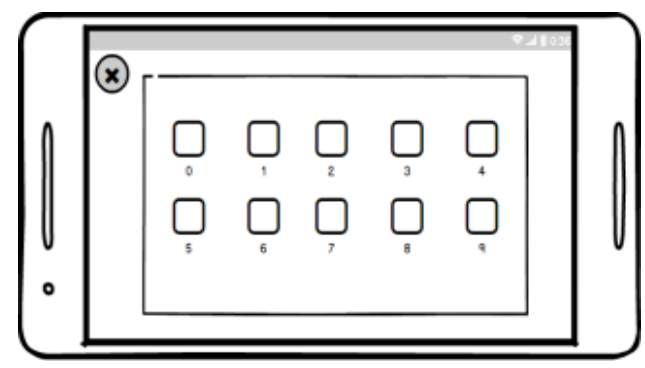

Gambar 7. Rancangan Layar Mengenal Angka

Gambar diatas merupakan rancangan layar halaman angka, yang merupakan halaman yang memperlajari jenis jenis angka.

\section{Rancangan Layar Mengenal Hewan}

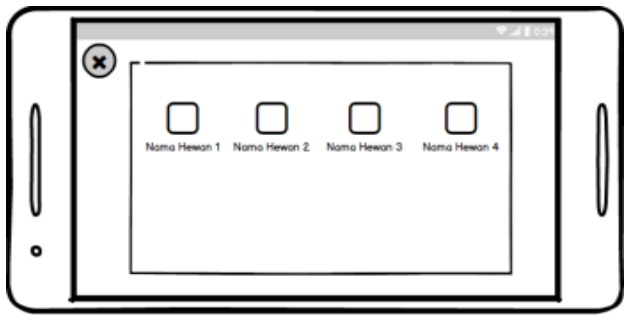

Gambar 8. Rancangan Layar Mengenal Hewan

Gambar diatas merupakan rancangan layar halaman hewan, yang merupakan halaman yang mempelajari jenis jenis hewan.

\section{Rancangan Layar Mengenal Buah}

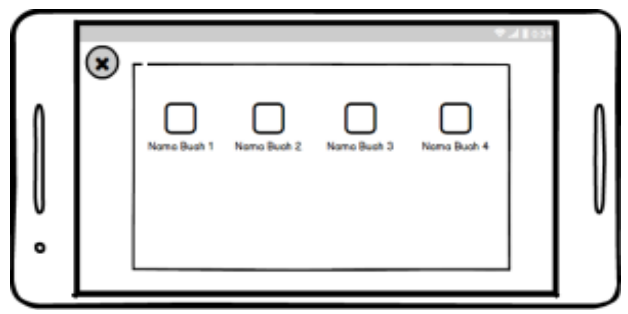

Gambar 9. Rancangan Layar Mengenal Buah

Gambar diatas merupakan rancangan layar halaman buah, yang merupakan halaman yang mempelajari jenis jenis buah.

\section{Rancangan Layar Soal Latihan}

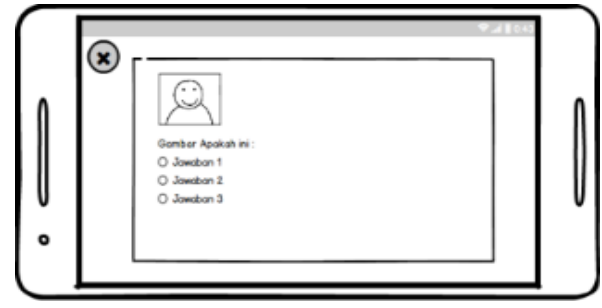

Gambar 10. Rancangan Layar Soal Latihan
Gambar diatas merupakan rancangan layar halaman latihan soal, sebagai evaluasi pemahaman pengguna aplikasi multimedia pembelajaran.

Tahap Pengkodean (coding) merupakan proses menerjemahkan desain kedalam suatu bahasa yang biasa dimengerti oleh komputer dan smartphone. Pada pengkodean ini penulis menggunakan bahasa pemrograman berbasis web yaitu PHP dan MySQL serta bahasa pemrograman berbasis android yaitu Java.

Pada tahapan implementasi merupakan bentuk aplikasi dari rancangan sebelumnya. Adapun tampilan layar aplikasinya dapat dilihat dalam gambar berikut.

\section{Tampilan Layar Dashboard}

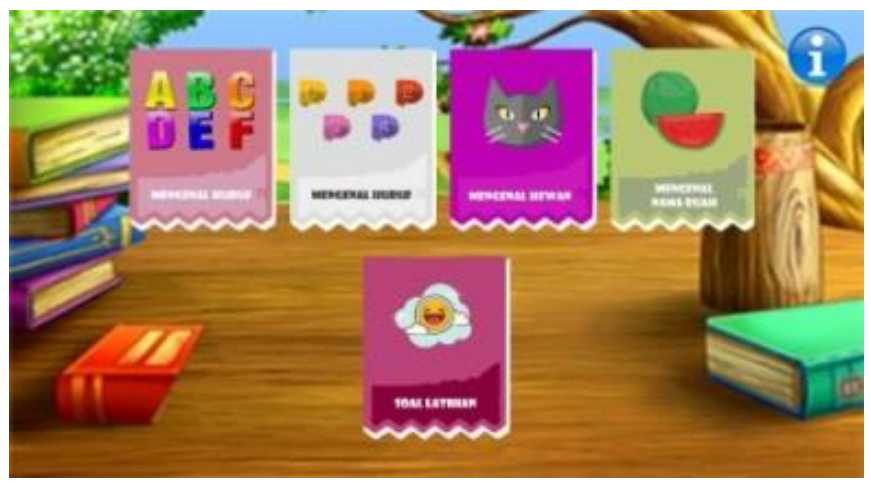

Gambar 11. Tampilan Layar Dashboard

\section{Tampilan Layar Mengenal Huruf}

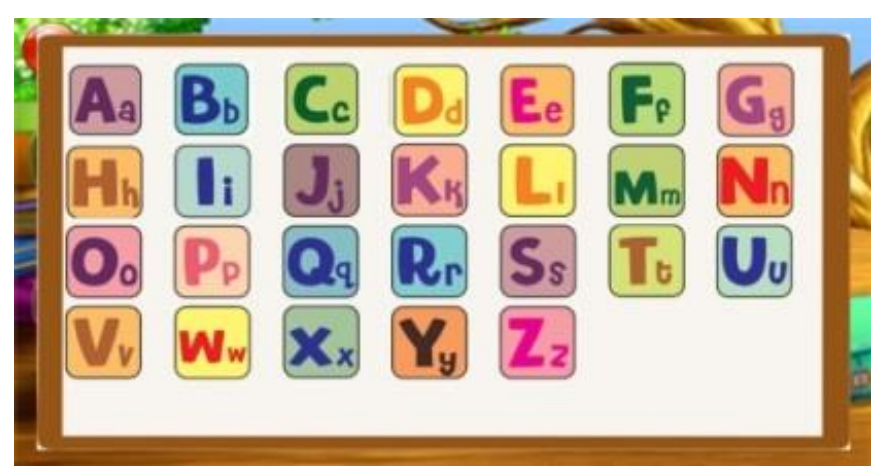

Gambar 12. Tampilan Layar Mengenal Huruf

\section{Tampilan Layar Mengenal Angka}

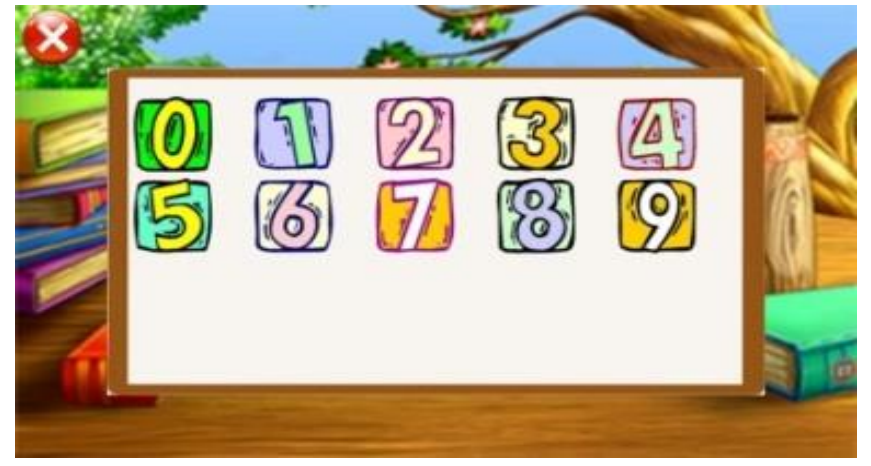

Gambar 13. Tampilan Layar Mengenal Angka 


\section{Tampilan Layar Mengenal Hewan}

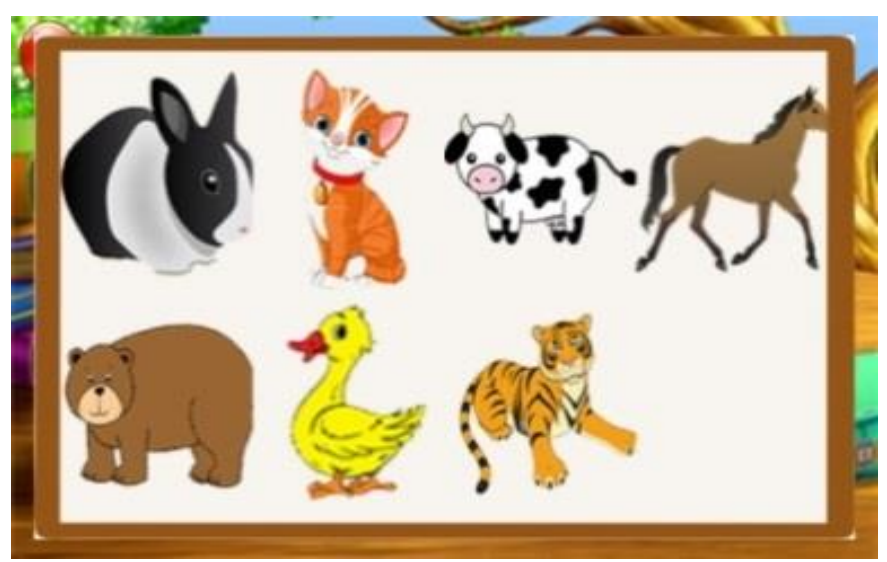

Gambar 14. Tampilan Layar Mengenal Hewan

Tampilan Layar Mengenal Buah

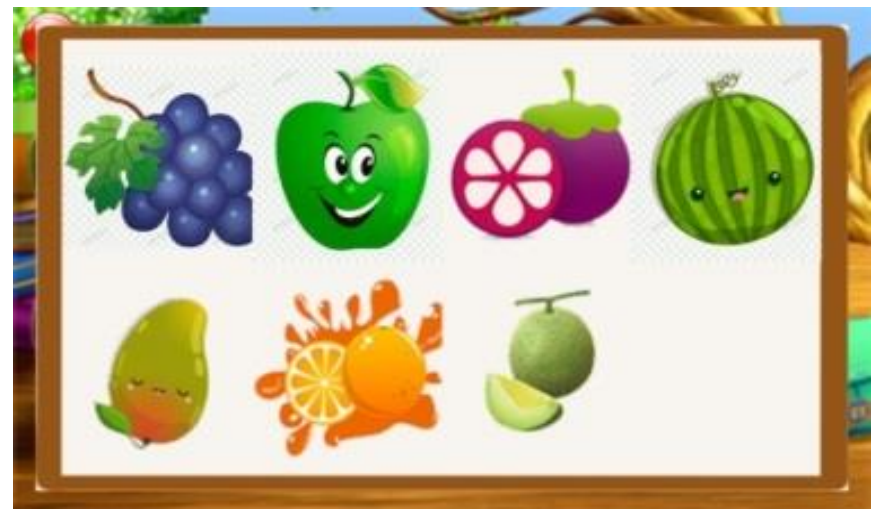

Gambar 15. Tampilan Layar Mengenal Buah

Tampilan Layar Soal Latihan

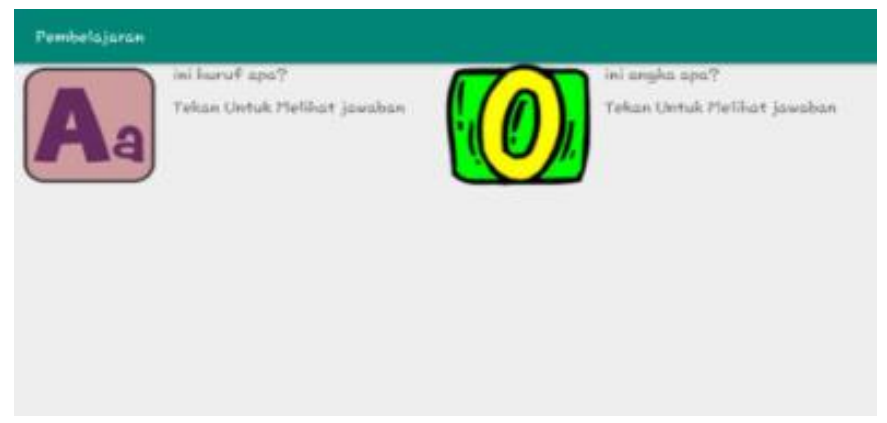

Gambar 16. Tampilan Layar Soal Latihan

Proses pengujian berfokus pada logika internal software, memastikan bahwa semua pernyataan sudah diuji, pada eksternal fungsional, yaitu mengarahkan pengujian untuk menemukan kesalahan-kesalahan dan memastikan bahwa input yang dibatasi akan memberikan hasil aktual yang sesuai dengan hasil yang dibutuhkan. Pada penelitian ini penulis menggunakan teknil black box untuk menguji fitur-fitur sistem yang telah dibangun.

Pada tahap pengujian ini, aplikasi multimedia pembelajaran diuji menggunakan blackbox testing.
Adapun pengujian Blackbox dapat dilihat pada tabel 5 . Berikut.

Tabel 5. Pengujian Black Box Aplikasi Android

\begin{tabular}{|c|c|c|c|}
\hline $\begin{array}{c}\text { Jenis } \\
\text { Pengujian }\end{array}$ & $\begin{array}{l}\text { Prosedur } \\
\text { Pengujian }\end{array}$ & $\begin{array}{l}\text { Hasil yang } \\
\text { Diharapkan }\end{array}$ & Validasi \\
\hline $\begin{array}{c}\text { Tampil } \\
\text { SplashScree } \\
\mathrm{n}\end{array}$ & $\begin{array}{l}\text { Pengguna } \\
\text { membuka } \\
\text { aplikasi }\end{array}$ & $\begin{array}{l}\text { Menampilkan } \\
\text { splash screen }\end{array}$ & Berhasil \\
\hline $\begin{array}{c}\text { Mengenal } \\
\text { Huruf }\end{array}$ & $\begin{array}{l}\text { Pengguna } \\
\text { memilih } \\
\text { menu } \\
\text { mengenal } \\
\text { huruf }\end{array}$ & $\begin{array}{c}\text { Menampilkan } \\
\text { pengenalan } \\
\text { huruf, dan suara }\end{array}$ & Berhasil \\
\hline $\begin{array}{c}\text { Mengenal } \\
\text { Angka }\end{array}$ & $\begin{array}{l}\text { Pengguna } \\
\text { memilih } \\
\text { menu } \\
\text { mengenal } \\
\text { Angka }\end{array}$ & $\begin{array}{l}\text { Menampilkan } \\
\text { pengenalan } \\
\text { Angka, dan } \\
\text { suara }\end{array}$ & Berhasil \\
\hline $\begin{array}{l}\text { Mengenal } \\
\text { Hewan }\end{array}$ & $\begin{array}{l}\text { Pengguna } \\
\text { memilih } \\
\text { menu } \\
\text { mengenal } \\
\text { Hewan }\end{array}$ & $\begin{array}{c}\text { Menampilkan } \\
\text { pengenalan } \\
\text { Hewan, dan } \\
\text { suara }\end{array}$ & Berhasil \\
\hline $\begin{array}{l}\text { Mengenal } \\
\text { Buah }\end{array}$ & $\begin{array}{l}\text { Pengguna } \\
\text { memilih } \\
\text { menu } \\
\text { mengenal } \\
\text { Buah }\end{array}$ & $\begin{array}{c}\text { Menampilkan } \\
\text { pengenalan } \\
\text { Buah, dan suara }\end{array}$ & Berhasil \\
\hline Soal Latihan & $\begin{array}{l}\text { Pengguna } \\
\text { memilih } \\
\text { menu Soal } \\
\text { Latihan }\end{array}$ & $\begin{array}{c}\text { Menampilkan } \\
\text { soal latihan }\end{array}$ & Berhasil \\
\hline
\end{tabular}

\section{HASIL DAN PEMBAHASAN}

Dalam penelitian ini, penulis menggunakan teknik pengumpulan data menggunakan metode kuesioner, adapun data yang diperoleh menggunakan data primer yang bersifat data kuantitatif.

Adapun dalam mengumpulkan data, penulis memberikan kuesioner kepada 50 end user, sebagai testimoni setela $\mathrm{h}$ menggunakan aplikasi multimedia pembelajaran.

Adapun hasilnya dipaparkan dalam bentuk diagram berikut: 


\section{Apa yang dirasakan User setelah menggunakan Aplikasi Multimedia Pembelajaran}

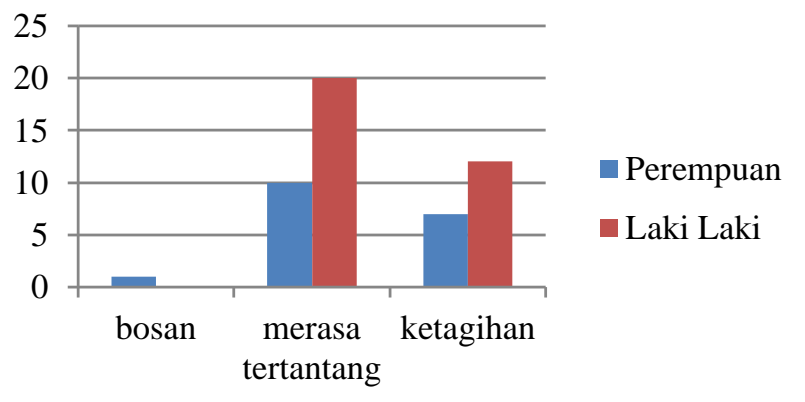

Gambar 17. Grafik Emotional user setelah menggunakan Aplikasi Multimedia Pembelajaran.

Gambar diatas menunjukan emotional dari user setelah menggunakan aplikasi multimedia pembelajaran. Berdasarkan gambar diatas bahwa sebanyak 30 user merasa tertantang setelah menggunakan aplikasi multimedia pembelajaran. dan 1 Orang yang merasa bosan setelah menggunakan aplikasi multimedia.

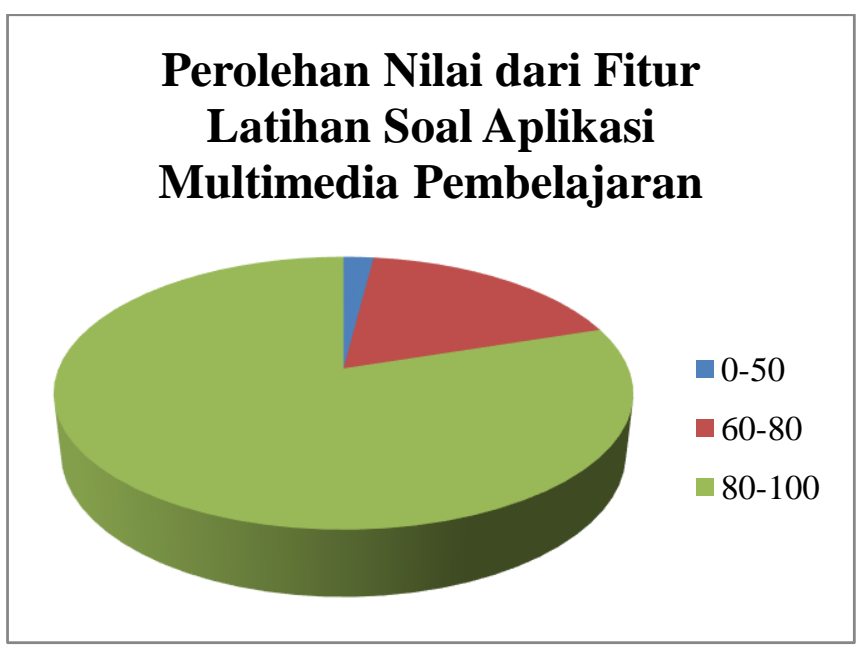

Gambar 18.Grafik Perolehan Nilai User

Gambar diatas menunjukan perolehan score dalam latihan soal pada aplikasi multimedia pembelajaran, berdasarkan data tersebut yang dari 50 end user, mayoritas memperoleh score 80-100, sedangkan yang mendapat nilai 0-50 hanya 1 orang.

\section{PENUTUP}

Aplikasi Multimedia Pembelajaran dapat meningkatkan minat belajar siswa, terbukti bahwa dalam penelitian ini menghasilkan diatas $50 \%$ user merasa tertantang dan ketagihan setelah menggunakan aplikasi multimedia pembelajaran., dan sekitar $80 \%$ user mendapat nilai kisaran
81-100 dalam latihan soal pemahaman materi pada aplikasi multimedia pembelajaran.

Dengan adanya aplikasi ini, pengguna dapat dengan mudah dan cepat menangkap pengetahuan dan materi yang sudah disiapkan di dalam aplikasi multimedia pembelajaran.

Aplikasi multimedia pembelajaran ini dapat dijadikan media pendukung dalam proses belajar mengajar, selain disampaikan di dalam kelas pengguna dapat mengulangi materi yang disampaikan dan juga dapat mengevaluasi pemmahaman materi secara cepat dan mudah dimanapun dan kapanpun. .

\section{ACKNOWLEDGMENT}

Terima kasih kepada Ibu Suzzana selaku Kepala Sekolah di SD Swadaya Pangkalpinang, yang telah membantu dan mengizinkan kami untuk melakukan penelitian dan riset di tempat, sehingga bisa terlaksana dengan lancar.

\section{REFERENCES}

[1] Dara Dwi Handayani, "Aplikasi Pembelajaran Dasar Kelas 1 SD Berbasis Android Pada SD Negeri 1 Pangkalan Baru," Jurnal STMIK Atma luhur Pangkalpinang : Pangkalpinang, 2015.

[2] Yudhiwan Nur Rokhim dan Husni Thamrin. "Perancangan Aplikasi Pembelajaran Pengenalan Warna, Huruf, dan Angka Untuk Anak Usia Dini Dengan 3 Bahasa Berbasis Android". Jurnal Universitas Muhammadiyah Surakarta : Surakarta, 2014.

[3] Aprih Widayanto dan Linda Refianti, "Aplikasi Pembelajaran Huruf, Angka, Warna, Hewan, Sayur Dan Buah Berbasis Android", Jurnal Evolusi Volume 6 No 2, 2018.

[4] Indrawan Dwi Bramastya, "Aplikasi Edukatif Pengenalan Huruf dan Angka Untuk Anak Usia Dini Berbasis Android". Universitas Muhammadiyah Surakarta : Surakarta, 2016.

[5] Abdul Rokhim dan NurulFuad, "Pembuatan Aplikasi Pengenalan Huruf Alfabet Untuk Anak Balita Pada Sistem Operasi Android". Jurnal SPIRIT Vol. 7 No. 2 Nopember 2015, hal 48-52, . 2015.

[6] Sri Mulyani, "Analisis dan Perancangan Sistem Informasi Manajemen Keuangan Daerah,”: Notasi Pemodelan Unified Modeling Language (UML). Abdi Sistematika : Bandung, 2016.

[7] Jeperson Hutahaean. 2015. Konsep Sistem Informasi . CV Budi Utama Yogyakarta

[8] Moh Suardi . 2018. Belajar \& Pembelajaran. CV Budi Utama : Yogyakarta

[9] T. Sugihartono, and Burham Isnanto, “ Prototipe Multimedia Pembelajaran Tilawatil Quran Berbasis Android pada TPA XYZ ,’Jurnal Teknologi Informatika dan Komputer Atma Luhur., vol. 03, no. 01 Maret, pp. 53-60, 2016.

[10] T. Sugihartono, "Implementasi Sistem Pendukung Keputusan Penerima Bantuan Rumah Tidak Layak Huni Berbasis Web," J. Sisfokom (Sistem Inf. dan Komputer), vol. 7, no. 1, hal. 52, 2018.

[11] Hakim dan Muhammad Rizki. 2012. Prototype Sistem Informasi Akademik Berbasis Mobile Menggunakan Java Script Object Notation (JSON). STIKOM Surabaya. Surabaya

[12] Mustaqbal, M. Sidi, Roero Fajri Firdus, Hendra Rahmadi 2015. Pengujian Aplikasi Menggunakan Black Box Testing Boundary Value Analysis. Jurnal Ilmiah Teknologi Informasi Terapan Vol.1, No.3. 